tổn thương động mạch cành và một số yếu tố liên quan ở bệnh nhân bệnh thận mạn lọc máu chu kỳ", Luân án tiến sĩ, Trường đai họ Ỵ Dược Huế 2020.

5. Lề Thị Đan Thùy, Phạm Văn Bùi, "Khảo sát nồng độ canxi, phospho, hormone tuyến cânn giáp ở bệnh nhân bệnh thận mạn loc máu chu kỳ và lọc màng bụng liên tục ngoaii trú tại Bệnh viện Bình Dân", 2019, Y Học TP. Hồ Chí Minh, Phụ Bản Tập 23, Số 3, 2019, tr $234-240$.

6. Nguyê̂n Hoàng Thanh Vần, "Nghiên cứu nồng độ Beta-crosslaps, hormone tuyến cận giáp huyết thanh ở bênh nhân bệnh thận mạn giai đoạn cuối", Luận aán tiến sĩ, Trường đại học Y Dược Huế 2015.

7. Nguyển Hữu Vũ Quang, "Nghiên cứu nồng đô FGF-23 huyết thanh và môi liên quuan với một số rổi loạn khoáng xương ở bệnh nhân bệnh thận mạn", Luận án tiễn sĩ, Trường đại học Y Dược Huế 2020.

8. Waziri B, Duarte $\mathbf{R}$, Naicker $\mathbf{S}$, "Biochemical markers of mineral bone disorder in South African patients on maintenance haemodialysis", African Health Sciences Vol 17 Issue 2, June, 2017: 445 - 452.

9. Wang WH, Chen LW, Lee CC, et al, "Association between Parathyroid Hormone, $25(\mathrm{OH})$ Vitamin D, and Chronic Kidney Disease: A Population-Based Study", BioMed Research International, Volume 2017, Article ID 7435657, 9 pages.

10. Ana $\mathbf{P}$, Luís $\mathbf{S}$, Hugo GF, "The calcium/ phosphous homeostasis in chronic kidney disease: from clinical epidemiology to pathophysiology", Acta Med Port,2017, 30(6): 485-49.

\title{
NGHIÊN CỨU ĐĂC ĐIỂM LÂM SÀNG VÀ KẾT QUẢ THANG ĐIỂM YMRS Ở BÊ̂NH NHÂN RỐI LOẠN LƯỠNG CỰC
}

Đinh Việt Hùng 1

\section{TÓM TẮT}

Mục tiêu: Nghiên cứu đặc điểm lâm sàng rối loạn lưỡng cực bằng thang điểm YMRS. Đối tượng và phương pháp nghiên cứu: 51 bệnh nhân rối loạn lưỡng cực được điều trị nội trú tại Khoa Tâm thần, Bệnh viện Quân y 103. Kết quả: Hoang tưởng tự cao gặp nhiều nhất chiếm $84,21 \%$ và tăng khí sắc gặp 92,16\%. Có 88,24\% bệnh nhân tăng hoạt động và sự chi phối hành vi chiếm $71,05 \%$. Khi bệnh nhân vào viện thì điểm trung bình YMRS 34,18 \pm 11,25 điểm; sau 3 tuân điều trị thì điểm trung bình YMRS 13,63 \pm 5,74 điểm. Kết quả điều tri bệnh nhân dùng kết hợp olanzapin và encorate là 9,16 $\pm 2,94$ điểm. Kết luận: Lâm sàng ở bênh nhân rối loạn lưỡng cực rất đa dạng và phong phú. Thang điểm YMRS là một công cụ khách quan để đánh giá giá tri các triệu chứng lâm sàng của bệnh nhân rối loạn lưỡng cực.

Tư khóa: Rối loạn lưỡng cực, thang điểm YMRS

\section{SUMMARY}

STUDY CLINICAL FEATURES AND RESULT OF YMRSSCORE IN BIPOLAR DISORDER PATIENTS

Objective: To study clinical features of bipolar disorder patients by YMRS score. Method: The sample was composed by 51 bipolar disorder patients admitted as in-patients to Psychiatry Department, 103 Military Hospital. Results: Grandiose delusion and elevated mood are the most popular symptoms, accounting for $84.21 \%$ and $92.16 \%$ in sequence. There are $88.24 \%$ patients who had increased goaldirected activity and the number of patients whose behaviors had been controlled is $71.05 \%$. When the patients were admitted to the hospital, average YMRS

${ }^{1}$ Bênh viện Quân y 103-Học viện Quân y

Chịu trách nhiệm chính: Đinh Việt Hùng

Email: bshunga6@gmail.com

Ngày nhận bài: 24.6.2021

Ngày phản biên khoa hoc: 20.8.2021

Ngày duyệt băi: 26.8.2021 score was $34.18 \pm 11.25$ point and after 3 weeks of treatment, the score was $13.63 \pm 5.74$ point. In patients who were treated by olanzapin and encorate, the score was $9.16 \pm 2.94$ point. Conlusion: Clinical feartures in bipolar disorder patients are very diverse. YMRS score is objective tool to evaluate the worth of clinical symptoms of bipolar disorder patients

Key words. Bipolar disorder, YMRS score

\section{I. ĐĂT VẤN ĐỀ}

Rối loạn lưỡng cực là rối loạn tâm thân được đặc trưng bằng giai đoạn hưng cảm hoặc giai đoạn hưng cảm nhẹ, có phối hợp với giai đoạn trầm cảm trong quá trình phát triển của bệnh. Đây là rối loạn tâm thân nặng, bệnh sinh rất đa dạng và phức tạp gôm các yếu tố sinh học, yếu tố tâm lý, yếu tố môi trường và yếu tố nhân cách. Tỷ lệ mắc rối loạn lưỡng cực vào khoảng 0,4-1,6\% với các rối loạn lưỡng cực I, rối loạn lưỡng cực II, khí sắc chu kỳ và hưng cảm nhẹ. Đến nay, nghiên cứu về rối loạn lưỡng cực, đặc biệt là giai đoạn hưng cảm, mới chỉ dừng lại ở phân tích các đặc điểm lâm sàng. Chưa có nhiêu nghiên cứu đề cập kĩ về các thang điểm trong đánh giá lâm sàng. Để góp phân tìm hiểu kỹ hơn bệnh cảnh lâm sàng trong rối loạn lưỡng cực, chúng tôi tiến hành nghiên cứu đăc điểm lấm sàng và kết quả thang điểm YMRS ở bệnh nhân rối loạn lưỡng cực.

\section{II. ĐỐI TƯợNG VÀ PHƯƠNG PHÁP NGHIÊN CỨU}

2.1. Đối tượng nghiên cứu. Đối tượng nghiên cứu gồm 51 bệnh nhân đáp ứng đây đủ tiêu chuẩn chẩn đoán rối loạn lưỡng cực theo ICD-10 điều trị nội trú tại Khoa Tâm thần-Bệnh viện Quân y 103 từ tháng 5/2020 đến tháng 5/2021. 
2.2. Phương pháp nghiên cứu. Sử dụng phương pháp nghiên cứu hồi cứu mô tả cắt ngang, phân tích đánh giá từng trường hợp cụ thể, các triệu chứng lâm sàng được đánh giá trong ngày đầu bệnh nhân vào viện.

Thang điểm đánh giá YMRS (Young Manic Rating Scale) được đánh giá 11 đề mục, trong đó có 7 đề muc đầu có điểm từ $0-4$ và 4 đề mục còn lại có điểm từ 0-8. Kết quả: Điểm YMRS 0-2 điểm: Bình thường, YMRS 3-11 điểm: Trầm cảm, YMRS 12-19 điểm: Hưng cảm nhẹ, YMRS $\geq 20$ điểm: Rối loạn lưỡng cức.

2.3. Phân tích số liệu. Phân tích số liêu được tiến hành trên phần mềm phân tích số liệu SPSS 20.0. Sự khác biệt có ý nghĩa thống kê được xác định cho các kiểm định với mức $p<0,05$.

\section{KẾT QUẢ NGHIÊN CứU VÀ BÀN LUÂ̂N \\ 3.1. Đặc điểm chung}

Bảng 3.1. Đặc điểm nhóm tuổi ở bệnh nhân nghiên cứu

\begin{tabular}{|c|c|c|}
\hline Nhóm tuổi số thống kê & $\begin{array}{c}\text { Số lượng } \\
\text { (n) }\end{array}$ & $\begin{array}{c}\text { Tỷ lệ } \\
\text { (\%) }\end{array}$ \\
\hline$\leq 20$ tuối & 2 & 3,92 \\
\hline $21-30$ & 22 & 43,14 \\
\hline $31-40$ & 8 & 15,69 \\
\hline $41-50$ & 13 & 25,49 \\
\hline$>50$ tuối & 6 & 11,76 \\
\hline Tuối trung bình & $27,17 \pm 10,31$ \\
\hline
\end{tabular}

Kết quả tại biểu đồ 3.1 cho thấy nhóm tuổi 21-30 là cao nhất $(43,14 \%)$, tiếp theo là nhóm tuổi 41-50 (22,58\%), thấp nhất là lứa tuổi $\leq 20$ tuổi chỉ chiếm có $3,92 \%$ và tuổi trung bình là 27,17 \pm 10,31 tuối. Theo Cazorla P. (2013) nghiên cứu ở 977 bệnh nhân rối loạn lưỡng cực thấy nhóm tuổi bệnh nhân hay gặp là nhóm tuổi 35-45 tuổi, với tuổi trung bình là 38,8 $\pm 12,1$ tuổi. Như vậy nghiên cứu của chúng tôi cho kết quả khác biệt bởi số liệu thu thập tại đơn vị điều trị tuyến cuối về tâm thần, bệnh nhân vào viện đa số là cấp tính, nặng nề và lần đầu, điều đó ảnh hưởng đến tần suất nhóm tuổi bệnh nhân [1].

Bảng 3.2. Đặc điểm giới tính ở bệnh nhân nghiên cứu

\begin{tabular}{|c|c|c|}
\hline $\begin{array}{c}\text { Chỉ số thống kê } \\
\text { Giơoi tính }\end{array}$ & $\begin{array}{c}\text { Số lượng } \\
\text { (n) }\end{array}$ & $\begin{array}{c}\text { Tỷ lệ } \\
\text { (\%) }\end{array}$ \\
\hline Nam & 20 & 39,22 \\
\hline Nữ & 31 & 60,78 \\
\hline
\end{tabular}

Kết quả Bảng 3.2 cho thấy: Nam giới chiếm tỳ lệ $39,22 \%$, nữ giới chiếm tỷ lệ là $60,78 \%$ và tỷ lệ phân bố theo giới tính ở nữ và nam là 1,55 . Kết quả nghiên cứu của chúng tôi tương đồng với nhận định của Prisciandaro J.J. (2016) trong nghiên cứu ở bệnh nhân rối loạn lưỡng cực thây nữ giới chiếm tỷ lệ $57,8 \%$, nam giới chiếm $42,2 \%$. Tác giả nhận thấy tỳ lệ nữ giới mắc tỷ cao hơn nam giới bởi phụ nữ có nhiêu giai đoạn bất lợi như sinh đẻ, tiền mãn kinh và tuổi thọ kéo dài. Hơn nữa trong cuộc sống phụ nữ bị chi phối nhiều các hoàn cảnh khách quan của cuộc sống như tín ngưỡng, tôn giáo, công việc và thiên chức người mẹ, người vợ [2].

Bảng 3.3. Đặc điểm tiền sử gia đình ở bệnh nhân nghiên cứu

\begin{tabular}{|c|c|c|}
\hline Tiền sử gia đởinhốn & $\begin{array}{c}\text { Số lượng } \\
\text { (n) }\end{array}$ & $\begin{array}{c}\text { Tỷ lệ } \\
(\%)\end{array}$ \\
\hline $\begin{array}{c}\text { Có người bị rối loạn tâm } \\
\text { thần }\end{array}$ & 9 & 17,65 \\
\hline $\begin{array}{c}\text { Không có ai bị rối loạn } \\
\text { tâm thần }\end{array}$ & 42 & 82,35 \\
\hline
\end{tabular}

Kết quả tại Bảng 3.3 về tiền sử gia đình của đối tượng nghiên cứu, qua đó ta thấy: bệnh nhân có người trong gia đình bị rối loạn tâm thần chiếm tỷ lê $27,42 \%$. Gia đình không có ai bị rối loạn tâm thần chiếm tỷ lệ $72,58 \%$. Kết quả nghiên cứu của chúng tôi cũng phù hợp với nhận xét của Hui T.P. (2019) trong gia đình có người mắc bệnh tâm thần thì tỷ lệ con cháu của họ măcbệnh dao động từ 11-21\%, trong đó trẻ em có cha hoặc mẹ mắc chứng rối loạn này có khoảng $10-25 \%$ khả năng tự phát triển rối loạn. Trẻ em có cả cha và me bị rối loạn có cơ hội 10$50 \%$. $(0,036)$, điều này chứng tỏ các vai trò của các gen di truyền như INPP1, GSK3B, NR1D1, SLC6A4, COMT, DRD1, BDNF và NTRK2 trong bệnh sinh rối loan lưỡng cực [3].

3.2. Đặc điểm lâm sàng rôi loạn lưỡng cực

Bảng 3.4. Đặc điểm thời gian bị bệnh ở bệnh nhân nghiên cứu

\begin{tabular}{|c|c|c|}
\hline $\begin{array}{c}\text { Chỉ số thống kê } \\
\text { Thời gian bị bệnh }\end{array}$ & $\begin{array}{c}\text { Số } \\
\text { lướng } \\
\text { (n) }\end{array}$ & $\begin{array}{c}\text { Tỷ lệ } \\
\text { (\%) }\end{array}$ \\
\hline$\leq 5$ năm & 25 & 49,02 \\
\hline $6-10$ năm & 18 & 35,29 \\
\hline $11-15$ năm & 7 & 13,73 \\
\hline$>15$ năm & 1 & 1,96 \\
\hline Trung bình & \multicolumn{2}{|c|}{$4,57 \pm 2,49$} \\
\hline
\end{tabular}

Nghiên cứu của chúng tôi thấy rằng thời gian bị bệnh $\leq 5$ năm chiếm tỷ lệ cao $(49,02 \%)$, tiếp theo là $6-10$ năm $(35,29 \%),>15$ năm thấp nhất $(1,96 \%)$ và thời gian mang bệnh trung bình là $4,57 \pm 2,49$ năm. Điều này cho thấy rằng đa số bệnh nhân bị bệnh đã được đưa sớm tới bệnh viện bởi các triệu chứng lâm sàng của bệnh nhân ảnh hưởng lớn tới gia đình họ và xã hội như kích động, nói nhiều, đi lại nhiều, tiêu nhiều tiền...kết quả này tương đồng với nghiên cứu của VidalRubio S.L. (2018) thấy rằng thời gian bị bệnh 
của bệnh nhân rối loạn lưỡng cực là 3,38 $\pm 1,25$ năm [4].

Bảng 3.5. Số lần điều trị ở bệnh nhân nghiên cứu

\begin{tabular}{|c|c|c|}
\hline Số lân điều trị & $\begin{array}{c}\text { Chỉ số thống kề Số lượng } \\
\text { (n) }\end{array}$ & $\begin{array}{c}\text { Tỷ lệ } \\
\text { (\%) }\end{array}$ \\
\hline 1 lần & 3 & 5,88 \\
\hline $2-4$ lần & 27 & 52,95 \\
\hline $5-7$ lần & 16 & 31,37 \\
\hline$>7$ lần & 5 & 9,80 \\
\hline Trung bình & $4,35 \pm 2,38$ \\
\hline
\end{tabular}

Số lần điều trị bệnh nhân nhiều nhất là 2-4 lần chiếm $52,95 \%$; số lần điều trị thấp nhất là 1 lần chiếm $5,88 \%$ và số lần điều trị trung bình là $4,35 \pm 2,38$ lần. Điều này được giả thích bởi các bằng chứng lâm sàng đã chỉ ra rằng bệnh nhân rối loạn lưỡng cực phải điêu trị suốt đời, cơn thứ 3 trở đi bệnh nhân bước vào chu kỳ tái phát bệnh. Hơn nữa bệnh nhân rối loạn lưỡng cực sẽ có nhiều giai đoạn bệnh từ hưng cảm, hốn hợp xen kẽ giai đoạn trầm cảm, chính quá trình lâm sàng này làm quá trình tái phát bệnh nhiều lần dẫn đến bệnh nhân phải số lần điều trị tại bệnh viện tăng lển.

Bảng 3.5. Đặc điểm yếu tố liên quan ở bệnh nhân nghiên cứu

\begin{tabular}{|c|c|c|}
\hline Số lân điều trị thống kế & $\begin{array}{c}\text { Số lượng } \\
\text { (n) }\end{array}$ & $\begin{array}{c}\text { Tỷ lệ } \\
\text { (\%) }\end{array}$ \\
\hline Sau sang chấn & 7 & 13,73 \\
\hline Lạm dụng chất & 13 & 25,49 \\
\hline Không chấp hành điều trị & 31 & 60,78 \\
\hline
\end{tabular}

Các yễu tố liên quan đến bệnh nhân chủ yễu là không chấp hành phác đồ điều trị $(74,19 \%)$, có khoảng $(13,73 \%)$ bệnh nhân liên quan tới sang chấn. Điều này cho thấy quá trình điều trị bệnh kéo dài suốt cuộc đời nên dẫn đến việc chán trường khi phải dùng thuốc lâu dài, đớn thuốc chưa phù hợp với kinh tế của bệnh nhân, sự phủ định bệnh của bệnh nhân là những nguyên nhân chính để bệnh nhân không chấp hành phác đồ điều trị. Ngoài ra có 13 bệnh nhân lạm dụng chất (ma túy đá, thuốc lắc, rượu...) yếu tố này làm cho quá trình tái phát bệnh cao hơn, hiệu quả điều trị thấp. Số ít bệnh nhân không có sự chia sẻ động viên của gia đình, bạn bè, không có công ăn việc làm, chất lượng của sống kém...đó là các tác nhân sang chấn của bệnh nhân rối loạn lưỡng cực.

Bảng 3.6. Eặc điêm rôi loạn hinh thức tư duy ở bệnh nhân nghiên cứu

\begin{tabular}{|c|c|c|}
\hline Hình thức tư đự̂y & $\begin{array}{c}\text { Cố lượng } \\
\text { (n) }\end{array}$ & $\begin{array}{c}\text { Tỷ lệ } \\
\text { (\%) }\end{array}$ \\
\hline Tư duy tốc độ nhanh & 42 & 82,35 \\
\hline
\end{tabular}

\begin{tabular}{|c|c|c|}
\hline Tư duy dồn dập & 16 & 31,37 \\
\hline Tư duy không liên quan & 5 & 9,80 \\
\hline Tư duy ngắt quãng & 2 & 3,92 \\
\hline
\end{tabular}

Rối loạn hình thức tư duy là biểu hiện hay gặp nhất và dễ phát hiện nhất ở bệnh nhân trong đó tư duy tốc độ nhanh chiếm $82,35 \%$; tư duy ngắt quãng chiếm 3,92\%. Bệnh nhân tư duy tốc độ nhanh đó là người đối thoại chưa nói hết câu đối thoại, chủ đề chưa rõ ràng nhưng bệnh nhân đối đáp lại bằng nhiều chủ đề, tốc độ nhanh, các chủ đề liên quan, gắn kết ít, thậm chí có chủ đề không liên quan. Tốc độ tư duy này nhanh đến mức nhiều bệnh nhân như là độc thoại. Trong rối loạn lưỡng cực có số ít bệnh nhân có tư duy ngắt quãng điều này có thể do sự thiếu hụt serotonin, lo âu tạo ra. Chủ điểm của của bệnh nhân không liền mạch, có nhiều khoảng nghỉ, mất nhiều thời gian để gắn kết lại, có những bệnh nhân người đối thoại còn phải gợi ý, mớm lời giúp [5].

Bảng 3.7. Đặc điêm các hoang tưởng ở bệnh nhân nghiên cứu

\begin{tabular}{|c|c|c|}
\hline Hoang tưởng & $\begin{array}{c}\text { Chỉ số thống kế lượng } \\
\text { (n) }\end{array}$ & $\begin{array}{c}\text { Tỷ lệ } \\
\text { (\%) }\end{array}$ \\
\hline Hoang tưởng tự cao & 32 & 84,21 \\
\hline Hoang tưởng ghen tuông & 9 & 23,68 \\
\hline Hoang tưởng bị hại & 5 & 13,16 \\
\hline Hoang tưởng kỳ quái & 2 & 5,26 \\
\hline
\end{tabular}

Ngoài rối loan hình thức tư duy thì rối loan nội dung tư duy cũng thường gặp ở bệnh nhẩn rổi loạn lưỡng cưc. Nội dung tư duy thể hiện ở bốn hoang tưởng sau: hoang tưởng tự cao $(84,21 \%)$, hoang tưởng ghen tuông $(23,68 \%)$, hoang tưởng bị hại $(13,16 \%)$ và hoang tưởng kỳ quái $(5,26 \%)$. Hoang tưởng hay gặp nhất là hoang tưởng tự cao đây chính là nguyên nhân của các hành vi tiêu pha quá mức, ngoài khả năng kinh tế của bệnh nhân và gia đình bệnh nhân. Bệnh nhân lưôn cho rằng mình là thần thánh, là người có quyền cao chức trọng, nói chuyện được với thần thánh, thậm chí có cả hội chứng xâm nhập, họ thể giúp đỡ nhiều nhiều người. Có những bệnh nhân ảo tưởng về kinh tế luôn cho rằng mình nhiêu tiền của, có thể ban phát, giúp đỡ những người khó khăn trong khi bản thân mình không có việc làm, làm xe ôm, công nhân...Một số ít bệnh nhân luôn cho rằng mình có khả nằng điều khiển thời tiết, hô mưa gọi gió, có khả năng thay đổi số phận con người [6].

Bảng 3.8. Đặc điểm rối loạn cảm xúc ở bệnh nhân nghiên cứu

\begin{tabular}{|c|c|c|}
\hline Rối loạn cảm xức & $\begin{array}{c}\text { Cố lượng } \\
\text { (n) }\end{array}$ & $\begin{array}{c}\text { Tỷ lệ } \\
\text { (\%) }\end{array}$ \\
\hline Tăng khí sắc & 47 & 92,16 \\
\hline
\end{tabular}




\begin{tabular}{|c|c|c|}
\hline Cảm xúc bùng nổ & 27 & 52,94 \\
\hline Cảm xúc căng thằng & 15 & 29,41 \\
\hline Cảm xúc không ổn định & 11 & 21,57 \\
\hline
\end{tabular}

Rối loạn hay gặp và thể hiện rõ ra bên ngoài là rối loạn cảm xúc, triệu chứng tăng khí sắc gặp ở 92,16\%; tiếp đến là cảm xúc bùng nổ (52,94\%), cảm xúc căng thẳng $(29,41 \%)$ và cảm xúc không ổn định (21,57\%). Theo tiêu chuẩn chẩn đoán rối loạn lưỡng cực thì tiêu chuẩn trưởng có khí sắc tăng, triệu chứng này thể hiện rõ trên khuôn mặt được đánh giá bởi các chuyên gia tâm thần, triệu chứng này không chịu sự chi phối của các yếu tố chủ quan của bệnh nhân hay người thăm khám. Khí sắc tăng bền vững trong này và mất khả năng tự phê phán trong các hoạt động giao tiếp của bệnh nhân. Cảm xúc của bệnh nhân rất đa dạng từ bùng nổ cảm xúc đến cảm xúc căng thẳng và cảm xúc không ổn định. Cảm xúc bênh nhân thể hiên ở moi lúc moi nơi không phù hợp với hoàn cảnh, họ nói cười hát hò liên tục. Theo Bùi Quang Huy (2018), cảm xúc bệnh nhân thay đổi liên tục tử bùng nổ, vui vẻ có thể nhanh chóng chuyển sang nổi cáu, gây sự với người xung quanh [5].

Bảng 3.9. Đặc điểm rôi loạn hoạt động có ý chí ở bệnh nhân nghiên cứu

\begin{tabular}{|c|c|c|}
\hline Chî́i số thống kến hoạt động & $\begin{array}{c}\text { Số lượng } \\
\text { (n) }\end{array}$ & $\begin{array}{c}\text { Tỷ lệ } \\
\text { (\%) }\end{array}$ \\
\hline Tăng hoạt động, đi lại nhiều & 45 & 88,24 \\
\hline Thích can thiệp vào mọi việc & 39 & 76,47 \\
\hline Tiêu tiền nhiều & 29 & 56,86 \\
\hline Kích động vận động & 17 & 33,33 \\
\hline Chống đối điêuu trị & 7 & 13,73 \\
\hline
\end{tabular}

Các triệu chứng rối loạn hoạt động có ý chí là đặc điểm nổi bật của bệnh nhân rối loạn lưỡng cức ở giai đoan hưng cảm. Ở nghiên cứu của chúng tôi có $88,24 \%$ bệnh nhân tăng hoạt động, tiếp đến là thích can thiệp vào moi việc $(76,47 \%)$, tiêu tiền nhiều $(56,86 \%)$, kích động vận đông $(33,33 \%)$ và chống đối điều trị $(13,73 \%)$. Lâm sàng thể hiện bệnh nhân hoạt động liên tục, không biết mệt mỏi, bệnh nhân làm nhiều việc, nhiêu mục đích cùng lúc. Họ thích tham gia vào công việc của người khác, luôn đưa ra ý kiến của mình dù không phù hợp nhưng bắt người khác phải tuân theo. Số ít bệnh nhân chống đối và kích động, chính những hà̀nh vi này gây nguy hiểm cho chính bênh nhân và những người xung quanh. Kết quả này phù hợp với nhận định của Cao Tiến Đức (2017) trong rối loạn lưỡng cực bệnh nhân thường tăng hoạt động quá mức, họ luôn cho rằng mình lắm tiền nên các hoạt hoạt mua sắm vô tội vạ thường hiện hữu ở bệnh nhân [6].
Bảng 3.10. Đặc điểm rối loạn hoạt động bản năng ở bệnh nhân nghiên cứu

\begin{tabular}{|c|c|c|}
\hline $\begin{array}{l}\text { Chỉ số thống kê } \\
\text { Rôi loạn hoạt động }\end{array}$ & $\begin{array}{c}\text { Số lượng } \\
\text { (n) }\end{array}$ & $\begin{array}{l}\text { Tỷ lệ } \\
(\%)\end{array}$ \\
\hline Ăn uống kém & 33 & 64,71 \\
\hline Tăng ham muốn tình dục & 24 & 47,06 \\
\hline Giảm ham muốn tình dục & 13 & 25,49 \\
\hline Ý tưởng tự sát & 6 & 11,76 \\
\hline Cơn xung động vận động & 4 & 7,84 \\
\hline Hành vi tư sát & 1 & 1,96 \\
\hline
\end{tabular}

Bảng 3.10 cho thấy rối loạn hoạt động bản năng ở bệnh nhân hay gặp nhất là ắn uổng kém $(64,71 \%)$ và hành vi tự sát $(1,96 \%)$. Sự rối loạn các chất dopamin, acetylcholin, gamma aminobutyric acid cùng các hormon thyroid và prolactin làm cho hoạt động bản năng của bệnh nhân bị rối loạn. Nổi bật đầu tiên là ăn uống kém dù bệnh nhân hoạt động rất nhiều nhưng nhu cầu bổ xung năng lượng lại không tương đồng. Rối loạn bản năng tình dục cũng là triệu chứng hay gặp, đa số bệnh nhân tăng nhu câu tình dục về cả số lần quan hệ, thời gian quan hệ cũng như hình thức quan hệ, có những bệnh nhân còn có sở thích khoe các bộ phận sinh dục nơi công cộng. Dù có ít bệnh nhân có ý tưởng và hành vì tự sát, nhưng khi đã có những triệu chứng này thì tính mạng của bênh nhân sẽ bị đe dọa [6].

Bảng 3.11. Đặc điểm các rối loạn khác ở bệnh nhân nghiên cứu

\begin{tabular}{|c|c|c|}
\hline Chí số thống kế & $\begin{array}{c}\text { Số lượng } \\
\text { (n) }\end{array}$ & $\begin{array}{c}\text { Tỷ lện } \\
\text { (\%) }\end{array}$ \\
\hline Giám nhu cấu ngủ & 26 & 50,98 \\
\hline Giảm sự tập trung chú ý & 14 & 27,45 \\
\hline Lo âu & 9 & 17,65 \\
\hline
\end{tabular}

Ngoài các rối loạn cảm xúc, tư duy, khí sắc...bệnh nhân rối loạn lưỡng cực còn rối loạn giấc ngủ (mất ngủ, giảm nhu câu ngủ, mất cảm giác giấc ngủ) chiếm 50,98\%; giảm tập trung chú ý chiếm $27,45 \%$ và lo âu chiếm $17,65 \%$. Cơ chế bệnh sinh của rối loạn lưỡng cực ngoài cơ chế gen các nhà nghiên cứu đề cập nhiều về rối loạn các chất dẫn truyền thần kinh như dopamin và serotonin. Chính sự tăng dopamin ở khe sinap dẫn đến giảm nhu cầu ngủ, giảm serotoni ở khe sinap dẫn đến giảm sự tập trung chú ý và lo âu. Chính các triệu chứng trên làm cho chất lượng cuộc sống bệnh nhân kém, sự tuân thủ điều trị của bệnh nhân giảm. Trong đó lo âu là nguyên nhân chính dẫn đến sự tăng hoạt động của bệnh nhân và góp phần không nhỏ tạo nển ý tưởng và hành vi tự sát ở bệnh nhân. Kết quả này tương đồng với nhận định của Bùi Quang Huy (2018), giảm nhu cầu ngủ hay gặp bệnh nhân rối loạn 
lưỡng cực (bệnh nhân ngủ ít từ 2-4 tiếng, sáng dậy không mệt, không có cảm giác thèm ngủ), biểu hiện của sự mất tập trung chú ý là hiệu quả công việc không cao, lơ đãng trong sinh hoạt [5].

Bảng 3.12. Đặc điểm sự chi phối hành vi ơ bênh nhân nghiên cứu

\begin{tabular}{|c|c|c|}
\hline $\begin{array}{l}\text { Chỉ số thống kê } \\
\text { Sự chi phối }\end{array}$ & $\begin{array}{c}\text { Số lượng } \\
\text { (n) }\end{array}$ & $\begin{array}{l}\text { Tỷ lệ } \\
(\%)\end{array}$ \\
\hline Có chi phối hành vi & 27 & 71,05 \\
\hline Không chi phối hành vi & 11 & 28,95 \\
\hline
\end{tabular}

Bảng 3.12. cho thấy có 27 bệnh nhân bị chi phối hành vi $(71,05 \%)$, chỉ có 11 bệnh nhân không bị chi phối hành vi (28,95\%). Sự chi phối hành vi chủ yếu diễn ra ở 38 bệnh nhân có hoang tưởng đi kèm, đặc biệt là những bệnh nhân có hoang tưởng bị hại, hoang tưởng kỳ quái. Sự chi phối hành vi của bệnh nhân càng mãnh liệt hơn khi các hoang tưởng này đi kèm với bùng nổ khí sắc, kích động. Kết quả này cho thãy rằng bệnh nhân lưỡng cực có các hành vi kích động được chi phối bởi sự mất hài hòa trong nhận thức, cùng với các hoạt động cá nhân thay đổi [6].

3.3. Kểt quả thang điểm YMRS ở rối loạn lưỡng cực

Bảng 3.13. Điểm số YMRS ở bệnh nhân nghiên cứu

\begin{tabular}{|c|c|c|}
\hline $\begin{array}{l}\text { Chỉ số thống kê } \\
\text { Điểm YMRS }\end{array}$ & Số điểm & p \\
\hline Khám lân 1 & $34,18 \pm 11,25$ & $<$ \\
\hline Khám lần 2 & $13,63 \pm 5,74$ & 0,05 \\
\hline
\end{tabular}

Bảng 3.13 cho thấy khi khám lần 1 khi bênh nhân vào viên thì điểm trung bình YMRS là 34,18 $\pm 11,25$ điểm; sau 3 tuần điều trị thì điểm trung bình YMRS là 13,63 $\pm 5,74$ điểm. Như vậy kết quả trên đã phản ánh hiệu quả điều trị bệnh nhân, lúc vào viện đa số bệnh nhân được chẩn đoán mức độ vừa và nặng (với 6-8 triệu chứng), sau quá trình điều trị 3 tuân số bệnh nhân có $1-2$ triệu chứng chiếm tới 78,12\%; còn lại số ít bệnh nhân có 3-4 triệu chứng rối loạn, đặt biệt có 2 bệnh nhân phải điều trị bằng liệu pháp sốc điện. Kết quả này phù hợp với nghiên cứu của Quested D.J. (2021) thấy rằng điểm số trung bình YMRS giảm sau 4 tuần điều trị [7].

Bảng 3.14. Kết quả điều trị ở bệnh nhân nghiên cứu

\begin{tabular}{|c|c|c|}
\hline Sự chi phối & Lồ thống kề $\mathbf{1}$ & Lân $\mathbf{2}$ \\
\hline Nhóm 1 & $33,25 \pm$ & $17,56 \pm$ \\
& 11,31 & 7,48 \\
\hline \multirow{2}{*}{ Nhóm 2 } & $36,47 \pm$ & $15,52 \pm$ \\
& 10,29 & 6,17 \\
\hline Nhóm 3 & $35,18 \pm$ & $9,16 \pm$ \\
11,74 & 2,94 \\
\hline
\end{tabular}

Bảng 3.14 thể hiện kết quả điều trị bệnh nhân nhóm 1 (dùng thuốc olanzapin) 17,56 \pm 7,48 điểm, nhóm 2 (dùng thuốc encorate) 15,52 \pm 6,17 điểm, nhóm 3 (dùng kết hợp thuốc olanzapin và encorate) $9,16 \pm 2,94$ điểm. Kết quả này thể hiện hiệu quả điều trị rối loạn lưỡng cực bằng thuốc chỉnh khí sắc, đặc biệt là nhóm thuốc valproat acid, ngoài ra cũng minh chứng vai trò của các thuốc an thần thế hệ mới như olanzapin, risperidol... cũng có vai trò nhất định trong điều trị. Hơn nữa kết quả điều trị phản ánh sự kết hợp giữa thuốc an thần và thuốc chỉnh khí sắc trong hoàn cảnh không có điều kiện dùng nhóm thuốc lithium bởi giá thành đắt, không có xét nghiệm định lượng hàng ngày... Kết quả này tương tự nghiên cứu của Xu L. (2015) khi thấy hiệu quả điêuu trị ở nhóm dùng thuốc chỉnh khí sắc và thuốc an thần là $12,45 \pm 7,03$ điểm, nhóm dùng thuốc chỉnh khí sắc là 19,15 $\pm 6,48$ điểm và nhóm dùng thuốc an thần là $21,80 \pm$ 11,72 điểm [8].

\section{KẾT LUẬN}

Rối loạn tư duy bao gồm rối loạn hình thức và nội dung tư duy, với nội dung tư duy thì hoang tưởng tự cao $(84,21 \%)$, hoang tưởng ghen tuông $(23,68 \%)$ nổi bật. Các rối loạn cảm xúc hay gặp triệu chứng tăng khí sắc $(92,16 \%)$, tiếp đến là cảm xúc bùng nổ $(52,94 \%)$.

Rối loạn hoạt động có ý chí và bản năng có $88,24 \%$ bệnh nhân tăng hoạt động, 64,71\% ăn uống kém và $1,96 \%$ hành vi tự sát. Sự chi phối hành vi có 27 bệnh nhân chiếm 71,05\%.

Khi bệnh nhân vào viện thì điểm trung bình YMRS 34,18 $\pm 11,25$ điểm; sau 3 tuân điêu trị thì điểm trung bình YMRS 13,63 $\pm 5,74$ điểm. Kết quả điều trị bệnh nhân nhóm dùng olanzapin là 17,56 $\pm 7,48$ điểm, nhóm dùng encorate là $15,52 \pm 6,17$ điểm và nhóm dùng kết hợp olanzapin và encorate là 9,16 $\pm 2,94$ điểm.

\section{TÀI LIẸU THAM KHẢO}

1. Cazorla P., Zhao J., Mackle M. et al. (2013), "Asenapine effects on individual Young Mania Rating Scale items in bipolar disorder patients with acute manic or mixed episodes: a pooled analysis", Neuropsychiatr Dis Treat; 9: 409-413.

2. Prisciandaro J.J. and Tolliver K.B. (2016), "An item response theory evaluation of the young mania rating scale and the montgomery-asberg depression rating scale in the systematic treatment enhancement program for bipolar disorder (STEPBD)", J Affect Disord; 205: 73-80.

3. Hui T'.P., Kandola A., Shen L. et al. (2019), "A systematic review and meta-analysis of clinical predictors of lithium response in bipolar disorder", Acta Psychiatr Scand; 140(2): 94-115. 
4. Vidal-Rubio S.L., Balanzá-Martínez V., Cuenca M, et al. (2018), "Duration of euthymia and predominant polarity in bipolar disorder", J Affect Disord; 241: 356-359.

5. Bùi Quang Huy (2018), Rối loạn cảm xúc lưỡng cực chẩn đoán và điều trị, Nhà xuất bản Y học, Hà Nồi, trang 7-84.

6. Cao Tiến Đức (2017), Rối loạn khí sắc. Giáo trình Tâm thần học, Nhà xuất bản Quân đội Nhân dân, Hà Nội, trang 201-219.
7. Quested D.J., Gibson J.C., Sharpley A.L et al., (2021), "Melatonin In Acute Mania Investigation (MIAMI-UK). A randomized controlled trial of addon melatonin in bipolar disorder", Bipolar Disord; 23(2): 176-185

8. Xu L., Lu Y., Yang Y. et al. (2015), "Olanzapinevalproate combination versus olanzapine or valproate monotherapy in the treatment of bipolar I mania: a randomized controlled study in a Chinese population group", Neuropsychiatr Dis Treat; 11: 1265-1271.

\section{KẾT QUẢ ĐIỀU TRI BẢO TỒN VIÊM TUYẾN NƯỚC BỌT MANG TAI MẠN TÍNH}

\section{TÓM TẮT}

Các phương pháp điều trị bảo tồn viêm tuyến nước bot mang tai mạn tính ngày càng được quan tâm do điều trị phấu thuật cắt tuyên nước bợ có chi phí cao, nhiều biến chứng; bên cạnh đó, khả năng của các tuyến phục hồi chức năng hoặc không có triệu chứng sau khi loại bỏ tắc nghẽn đã được chứng minh bằng thực nghiểm và lâm sàng. Mục tiêu: Mô tả kết quả điểu trị bảo tồn viêm tuyến nước bot mang tai mạn tính trong một số tài liệu đã công bổ. Đối tượng và phương pháp nghiên cứu: Tổng quan và phân tích dữ liệu về kết quả điều trị bảo tồn viêm tuyến nước bọt mang tai mạn tính từ các bài báo, luận văn, luận án trên trang cở sở dữ liệu Pubmed, Google Scholar, EBSCOhost Research Databases. Kết quả: Tổng hợp trong 155 nghiên cứu lọc tên bài và phần giới thiệ̉u trên 3 trang cơ sở dữ liệu: Pubmed, Google Scholar, ESBCO host Research Databases được 32 nghiên cứu. Tiếp tục đánh giá chi tiết các tài liêu chon đước 5 tài liệu đạt tiêu chuẩn đưa vào phân tích: 3 nghiên cứu tiển cứu và 2 nghiên cứu thử nghiệm lâm sàng ngẫu nhiên có đối chứng. Kết quả phần tích cho thấy: điêu trị bảo tồn viêm tuyến nước bot mang tai mạn tính bằng bơm rửa hệ thống ống tuyến, có kết hợp với các chất chống viêm, kháng khuẩn có hiệu quả cao, với kết quả cải thiện chỉ số VAS rõ rệt so với trước điều trị và tỳ lệ tái phát thấp. Bệnh nhân được bớm rửa hể thống ổng tuyến bằng penicillin có kết quả điều trị ổn định, không tái phát sau 8 năm. Kết hợp nội soi và bơm rửa hệ thổng ống tuyến với betamethason cải thiên chỉ số VAS tốt hơn so với chỉ nội soi ống tuyến. Kết luận: Điêu trị bảo tồn viêm tuyến nước bọt mang tai mạn tính bằng bơm rửa hệ thống ống tuyến, có kểt hợp với các chất chống viêm, kháng khuẩn có hiệu quả cao, với kết quả cải thiện chỉ số VAS rõ rệt so với

1 Viện Đào tạo Răng hàm mặt, Trường Đại học Y Hà Nội 2 Trường Đại học Y Dược - Đại học Quốc Gia Hà Nội

Chịu trách nhiệm chính: Đặng Thị Hường

Email: huong03111982@gmail.com

Ngày nhận bài: 23.6.2021

Ngày phản biên khoa họ: 20.8.2021

Ngày duyệt bài: 27.8.2021
Từ khóa: kết quả, điều trị bảo tồn, viêm tuyến nước bọt mang tai mạn tính.

\section{SUMMARY}

\section{RESULTS OF CONSERVATIVE TREATMENT \\ OF CHRONIC RECURRENT PAROTITIS}

The conservative treatment methods for chronic recurrent parotitis are increasingly interested due to the high cost and complications of surgical treatment; In addition, the ability of the glands to restore function or be asymptomatic after removal of the obstruction has been demonstrated experimentally and clinically. Objectives: Describe the results of conservative treatment of chronic recurrent parotitis. Materials and methods: Review and analysis of data on conservative treatment of chronic recurrent parotitis from articles, theses and dissertations on Pubmed database, Google Scholar, EBSCOhost Research Databases. Results: Synthesized in 155 studies filtering the title and introduction on 3 databases: Pubmed, Google Scholar, ESBCO host Research Databases were 32 studies. Continuing to evaluate the literature in detail, 5 documents met the criteria for analysis: 3 prospective studies and 2 randomized controlled clinical trials. The results of the analysis showed that: conservative treatment of chronic recurrent parotitis with ductal irrigation, in combination with anti-inflammatory and antibacterial agents, is highly effective, with improved VAS index was markedly compared to before treatment and the recurrence rate was low. The patient was irrigated with penicillin with stable treatment results, no recurrence after 8 years. Combining sialendoscopy and irrigation of the ductal system with betamethasone improves VAS better than sialendoscopy alone. Conclusion: Conservative treatment of chronic parotitis with ductal irrigation, combined with antiinflammatory and antibacterial agents is highly effective, with significant improvement in VAS index compared with with pre-treatment and low recurrence rate.

Keywords: outcome, conservative treatment, chronic recurrent parotitis. 